University of Wollongong

Research Online

Faculty of Commerce - Papers (Archive)

Faculty of Business and Law

January 2005

\title{
Social and Commercial Sustainability of Regional Web-based Communities
}

\author{
A. Connery \\ University of Wollongong \\ Helen M. Hasan \\ University of Wollongong, hasan@uow.edu.au
}

Follow this and additional works at: https://ro.uow.edu.au/commpapers

Part of the Business Commons, and the Social and Behavioral Sciences Commons

\section{Recommended Citation}

Connery, A. and Hasan, Helen M.: Social and Commercial Sustainability of Regional Web-based Communities 2005.

https://ro.uow.edu.au/commpapers/283

Research Online is the open access institutional repository for the University of Wollongong. For further information contact the UOW Library: research-pubs@uow.edu.au 


\title{
Social and Commercial Sustainability of Regional Web-based Communities
}

\author{
Abstract \\ New information and communications technologies have disrupted many traditional forms of community \\ but enabled the emergence of new ones. This paper examines pertinent characteristics of communities, \\ before describing three case studies of commercially operated web-based communities. The research \\ demonstrates the social and commercial value of the concept of community. \\ Keywords \\ Web-based community, regional location, sustainability, social capital, economic value \\ Disciplines \\ Business | Social and Behavioral Sciences

\section{Publication Details} \\ This article was originally published as: Connery, A \& Hasan, $\mathrm{H}$, Social and Commercial Sustainability of \\ Regional Web-based Communities, International Journal of Web-Based Communities, 2005, 1(3), 246-261. \\ Copyright 2005 Inderscience. Original journal available here.
}




\title{
Social and Commercial Sustainability of Regional Web-based Communities
}

\author{
Andrew Connery and Helen Hasan \\ Department of Information Systems \\ University of Wollongong, Wollongong 2522, Australia \\ andrew@empoweraustralia.com \\ hasan@uow.edu.au
}

\begin{abstract}
New information and communications technologies have disrupted many traditional forms of community but enabled the emergence of new ones. This paper examines pertinent characteristics of communities, before describing three case studies of commercially operated web-based communities. The research demonstrates the social and commercial value of the concept of community.
\end{abstract}

\section{KEYWORDS}

Web-based community, regional location, sustainability, social capital, economic value

\section{Introduction}

The desirability of supporting and encouraging online communities to build social capital is now well documented (Preece 2000, Rheingold et al.). A group of people interacting via the Web is popularly referred to as a 'virtual community' which Koh and Kim (2001) define as one that is "extended via emerging technologies" whether 'online originated' or 'offline originated'. Following discussion that accompanied the presentation of earlier work on this project (Connery \& Hasan 2004), the authors have decided to no longer use the descriptor 'virtual' for such communities as they are believed to be as 'real' as any other. This decision will be reflected in this paper where the generic term 'community' will be used. The research presented here focuses on the development of communities that are essentially web-based but are situated in, and serve the needs of, a bounded local region. Although in such circumstances there usually exist offline links between members, a new sense of community can emerge in the online environment.

The capability of the Web to enable the creation and sustaining of communities is becoming increasingly more common for a wide range of activities, which can be in the commercial as well as non-profit or educational sectors. There is indeed a business imperative for intellectual capital creation which is a socially constructed dynamic process of situated collective knowing that is capable of being leveraged into economic and social value (O'Donnell et al 2003). Paradoxically, the problem of 'sustaining' a web-based community, in the intermediate and longer term, is not particularly well understood. The Internet landscape is littered with the remains of failed websites and no longer functioning portals, i.e. not updated recently or displaying any visible signs of interaction with some notable exceptions (see for example the report of Arthur-Anderson, 1999, and work of Skogseid \& Jansen 2001).

The problem of the sustainability of web-based communities (WBC) is now a widespread phenomenon, and is capturing the interest of researchers in many disciplines in academia and the professions. Some of the more successful communities, designated as 'communities of practice' (Wenger et al 2002), are sponsored by large commercial firms, while other online communities, loosely described as 'communities of interest' are managed by the members themselves. It can be argued that all 'successful' WBCs (including intranet, extranet and internet type portals) share this single characteristic, commonality of interest, notwithstanding any other stated policies or promoted objectives. This appears to be a necessary condition for both the creation and continuance of WBC, however there is also an increasing need for these communities to be commercially viable and demonstrate return of investment in a pragmatic sense. 
This paper will examine characteristics of communities in the era of the Internet, before describing a case study based on 30 months of action research in an Australian WBC set up as a regional community portal by a private company as a venture with the objective of becoming commercial viable in its own right. Outcomes of this study are described and compared with the situation in two subsequent exploratory cases, one for a large city market and one for a smaller country town. Criteria for success are discussed and evaluated from both the commercial and social perspectives.

\section{Communities in the era of the Internet}

The realisation of the importance of community is not new but like other concepts, such as that of .information, it was once taken for granted and has taken on more significance with the emergence of sophisticated information and communications technologies (ICT). Communities are collections of people that engage in activities that encompass a common interest, not only in their leisure time, but also as part of their work as employees of organisations or in classes at educational institutions. The influences of a modern lifestyle driven by new ICT, have disrupted many traditional forms of community but enabled the emergence of new ones. No longer is the local neighbourhood the only place where gossip is exchanged and the problems of the world are solved. Social exchange is just as likely to occur in chatrooms or appear as 'blogs' (weblogs) of anonymous participants from all over the world.

\subsection{Changing Characteristics of Communities}

People in skilled employment in developed western societies are time poor and feel the pressure of an everchanging workplace battling to meet the demands of the global economy. The Internet and global mass media have made people better informed and broadened their horizons while the functionality of the World Wide Web (WWW) has given them more flexibility and control of the transactions in their daily lives. There is a general up-skilling of the population now confident with computers or who have grown up with them. We can bank, shop, be entertained and informed any where, any time as long as we have access to the Internet and the skills to use it. The downturn in global travel due to cost and danger is another aspect of modern life that encourages the use of ICT such as tele- or video-conferencing for human interaction at a distance.

Some of the traditional characteristics of communities have endured in this new environment while many are undergoing change. , A number of studies have been done on the effect of size on communities (see for example Stoel 2002). It appears that the use of technology has not altered to any great extent the maximum number of people, around 9-12, that can work creatively as a team. It has also not increased the number of people with whom we can have a working acquaintance (around 150). We have anecdotal evidence that these numbers may be lower in stressful, technologically driven contexts. There is also a great deal of research into the richness of different communications and broadcast media such as face-to-face, video, audio, written, electronic (see for example Dennis \& Kinney 1998). Of particular concern in the online environment is the need for members of a community to feel the presence of others and considerable research has been done on the concept of 'social presence' (see for example Suh et al 2003).

Attempts to understand these evolving phenomena have uncovered various factors that appear to be of some importance. Koh and Kim (2001) treat online communities in terms of three dimensions: belonging, influence and immersion. Wenger et al (2002) also have three dimensions of communities of practice:

- What it is about - its joint enterprise as understood and continually renegotiated by its members

- How it functions - mutual engagement that bind members together into a social entity

- What capability it has produced - the shared repertoire of communal resources (routines, sensibilities, artifacts, vocabulary, styles, etc.) that members have developed over time.

Hasan and Crawford (2003a,b) list five elements that appear to be important to the socio-technical model when applied to genuine communities of people with common interests and goals as follows:

- Being clear about the purpose of community, including what can it achieve.

- Recognising the importance of diversity in the community and how different members are encouraged and their contribution valued.

- Encouraging a mix of work, learning and entertainment. 
- Taking into account how trust is developed in different modes of interaction, in particular face-toface and online.

- Noting how different characteristics and capabilities of the people and technology affect the viability of the community, identifying the functions of technology and skills of people to be enhanced.

\subsection{Contributions to Sustainability}

We propose that the continued viable existence of the online community is the most realistic measure of its success rather than the achievement of any other stated goals for which there are often no easily identifiable measures. In the research presented here, we consider both social and commercial aspects that contribute to their continued existence and sustainability. In doing so we are influenced by the trend in many enlightened organisations where the one 'bottom line' has become the 'triple bottom line', economic, plus environmental and social (Raeside \& Walker 2001). This has been particularly so in public and not-for-profit organisations but even many private companies are broadening their goals to include those of the triple bottom line. We feel that it is too early in our case to consider environmental issues but we will look at both economic and social determinants to the success of our WBC.

Recent research (Vrazalic et al 2003) reveals that there are numerous examples of WBCs, Community Portals and Business Portals established without heed to their social and economic value and with goals which do not directly address or recognise the fundamental requirement of having a common focus either of interest or practice. Many of these communities have failed to achieve and/or maintain a critical mass and suffered the consequences of not being sustained. Essentially, prospective community members must perceive a real need to participate in the first instance, but additionally and more importantly to become motivated to continue to return regularly to the site. "All communities must first meet one basic requirement: they must engage and involve members" (Cothrel \& Williams 1999). To this end, identifying informational/sociological need or needs that are not satisfactorily provided by any other organization/media is a key to establishing both social and commercial WBC value in the longer term. We argue that this fundamental requirement is a prerequisite for the successful establishment of any WBC and that all other developmental strategies adopted to grow and sustain the WBC must leverage off this requirement.

The initial project described in this paper is a WBC model that seems to work. It has added a solid business foundation to aspects of technological capability and social awareness that appear to be essential for success. It adopts a business model commonly used in the broadcast media of attracting advertising based on circulation data obtained through solid market research. It also takes advantage of the low transaction costs, information currency and flexibility of electronic media in comparison with paper distribution.

\section{The Research Problem and Design}

\subsection{The choice of research sites}

The research described here began with an action research study in 2003 of one instance of a locally-based WBC that appears to have developed a successful model for sustainability from both a commercial and social perspective. The initial case involves a regional community portal that has been designed to meet specific needs of that regional community. The region has a long-standing identity, which serves to give a solid foundation and focus to the portal. The owner, and director, of the project, also one of the researchers, has allowed it to evolve over the past 3 years with market research and investigations into the requirements and demands of the community, ensuring these remain paramount.

From a research standpoint this case was opportune as it brought together an innovative business venture with an academic research program that was investigating aspects and uses of Web technologies in communities. The case is analysed to determine possible reasons for its continued success, both commercially and socially, and used to predict the course of two projects underway that are using modifications of this model into different local situations.

Whereas the initial case was situated in a medium sized regional town with a well-defined and accepted identity, the research has been extended to study two subsequent sites which are, on the one hand, a less well- 
defined section of large city and, on the other, a much smaller country township. One aim of this part of the research is to determine characteristics of these secondary sites that differ from those that appeared to determine the success of the initial site. A second aim is to observe if and how the original model can be modified to suit the new situations.

\subsection{The method -Action Research in Case Studies}

There is a growing realisation in the field of Information Systems of the general research value that can be gained from the use of action research in a single case study or a small number of them (Walsham 1995). This is particularly true when the topic of concern relates to early adoption of cutting edge technology, as such endeavours may be the only source of reliable and relevant data, as the phenomenon of interest is emergent. For the topic of this paper, i.e. the commercial and social sustainability of WBC, it would be extremely difficult to use any other research method. To that end we will now describe the cases and present data demonstrating their achievements to date. We will then discuss the issues that emerge from our interpretation of the success of the communities to date.

\subsection{The research design and process}

The research began with the first indepth case study where an experienced researcher worked with the owner/manager of the business designing and managing the WBC who was beginning a research degree. Data was gathered and analysed from documentation plus descriptions and recollections from the owner manager in conjunction with feedback from contributors to the site and subscribers. The resulting case descriptions were then read and reconfirmed by the owner/manager. This process was continued for the second, expanded site by the same group. For the third site initial interviews were conducted with the site managers and representatives of the subscriber community. Data was then summarised in conjunction with review of the literature.

\section{The Initial Case}

\subsection{Attributes of the Local Community}

The community, for which the WBC was built, is a predominantly working-class, industrial town together with its surrounding coastal area, and includes several hundred thousand inhabitants. There is a strong sense of local identity and the area is going through some economic and social challenges with the downsizing of the main local industry with unemployment relatively high., Despite this, the region has a positive outlook with opportunities for growth in the tourism and education sectors. The region is large enough to have an integrated local area health service, a university, and arts centre, a daily newspaper and a local TV station. It surrounds an industrial coal/steel town with traditionally one large employer, a history of shared catastrophes (mines and bushfires) as well as challenges and competition from 2 neighbouring big cities. This has meant that the population is not blasé about community values. People are also drawn together in support of local sports teams in the national competitions of football and basketball, with associated well-known local heroes.

Among the many issues that continually challenge regional communities is the need for local content in the media. The key, identifying characteristics of a local community, in terms of media, is that they are usually dominated by national networks for electronic media (TV and radio) and serviced by a single newspaper, owned by a national publishing company. Most editorial content is provided top down with limited local content and, importantly, the bulk of advertising revenue is earned from national advertisers. This usually means that local advertisers are cross-subsidised creating a situation where it is difficult for locally-based media owners to compete and provide local content. This results in a distortion of the market, which does not have the financial or social capital to correct. This problem is common to all regional areas. What is new, and the objective of this innovative project, is the realisation that there is an opportunity to remedy this in a virtual space by providing local content by local on a low cost advertising model. 


\subsection{Co-evolution of Research and Practice}

The project began when a strategic alliance developed between Empower Australia, a well-established local media representative group, which had also published in it own right, Internetrix, a locally-based software developer and the DMW group, a financial partner. The group felt that the Internet could be the means to remedy the problems caused to regional communities by the stranglehold of large national consortia, stifling local content in the public media. They began cautiously, somewhat bewildered by the euphoria of the, then, boom in Internet-based activity. Following the subsequent dot.com crash, they were encouraged by the confidence that their combination of skills and knowledge would be equal to others in the field. The objective was to conduct an entrepreneurial endeavour to establish a WBC, capitalising on the core skills of Empower in tradition publishing, marketing and selling advertising, in the belief that an opportunity existed to utilise the power of the Internet while utilising traditional business methods. The project was supported by action research using marketing principles to understand the potential of web-based media and this research focus grew into links with Information System's researchers at the local University. This project attracted considerable attention at local and state government levels and was launched by the state premier at the inaugural Innovation Week 2001 at the University’s public Science Centre.

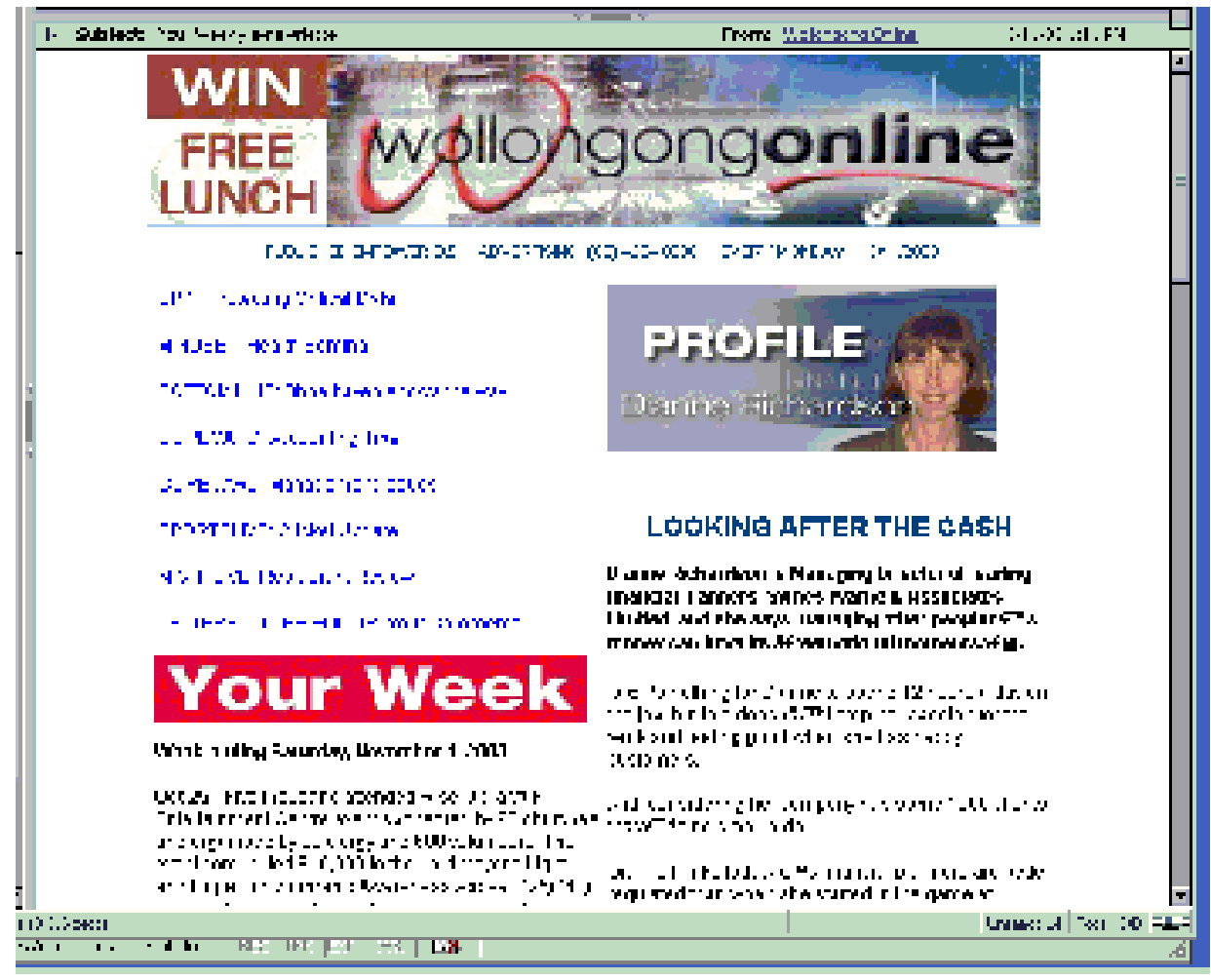

Figure 1 Part of a $1^{\text {st }}$ generation e-Zine 


\subsection{Description of the WBC}

The WBC began as portal (www.wollongongonline.com) with associated weekly e-newsletter as shown in Figure 1. The main section of the e-newsletter was designed as two column pages, using the familiar format of a magazine. This enabled subscribers to clearly distinguish advertising from content, which included short opinion articles from local people. The project worked as an e-Zine, sent every Monday as HTML to the email address of subscribers, and linked back to the portal the original version of which is shown in Figure 2. Circulation was increased by referrals from current subscribers and the e_Zine was not pushed in the sense of email spam.

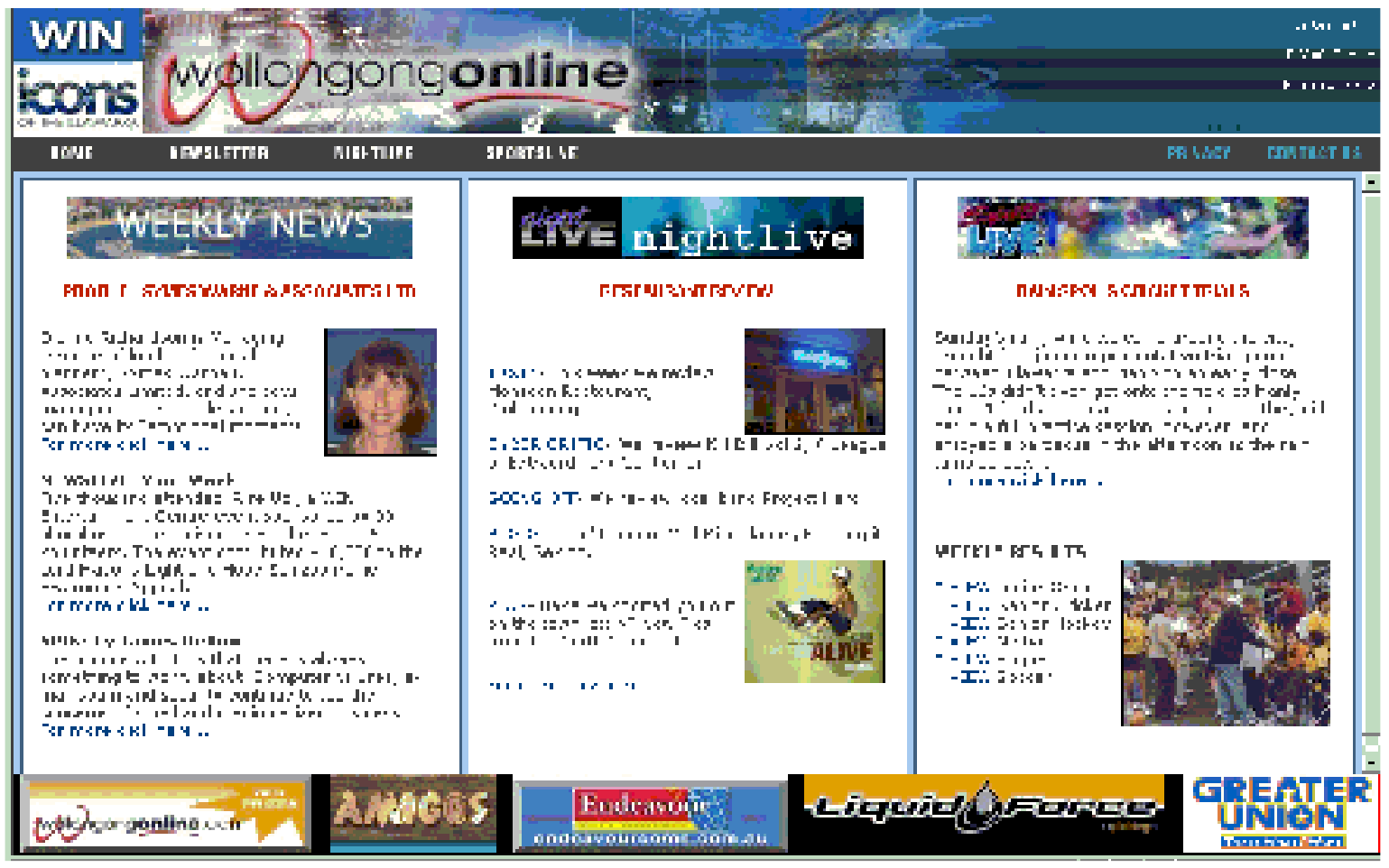

Figure 2 The Community Portal as of November 2003

Feedback from constant market research has evolved the design and content over the life of the site. Features that were introduced early in its life were the ability for subscribers to give their feedback on the opinion pieces and an evolving section for local amateur sporting groups. The community served by the portal has always had a strong sporting heritage but the local newspaper, owned by a nation-wide group, mainly reported on local professional teams in national competitions such as football and basketball. This resulted in the portal now being designed as three portlets, as can be seen in Figure 2, for local news, sport and entertainment with appropriate domain names acquired as part of the business plan, including www.wollongong.youronlinecommunity.com.au www.newslive.com.au www.sportslive.com.au and www.nightlive.com.au The latter sends alerts to subscribers rather that be a full e-Zine and is becoming popular with the local youth.

\subsection{Philosophy and heuristics}

The action research, undertaken in the region to be serviced by the WBC, experimented with a number of different strategies and developed a set of five guiding philosophies or heuristics for the WBC:

- Online activities were to replicate offline activities as closely as possible if it doesn't happen in the real world it shouldn't be in a WBC either. A clearly defined membership base would reduce the need to cater for cultural differences 
- 'Old Economy' publishing and marketing methodologies would be utilised. It was found that market forces remain constant on- or offline. Offerings should be targeted to an identified demographic

- The primary and over -riding strategic goal would be to find ways for the project alliance to sustain the WBC economically in the intermediate and longer term since, as is often the case, governmental/corporate seed funding was only available short term for the project

- The WBC operators are to be committed solely to web publishing and not an adjunct to any other media (TV, newspapers), government utility, institution, company or community organisation

- The internet culture / language of members was accepted and no content was prescribed or overly censored ie freedom of speech first, political correctness second. Credibility and trust would be built through allowing the community to shape opinion and discussion.

These guiding principles, determined early in the project, have been regularly tested and continued to apply.

\subsection{Outcomes}

As mentioned previously the success of the community would be determined on both social and economic criteria. Commercial performance measures such as profitability and return on investment would apply. However, the amount of activity on, and interest in, the portlets, within their targeted demographics, would be more an indication of the social success of the WBC.

There is no doubt that this WBC project is becoming increasingly successful, for an innovative venture of this kind, on both the social and economic criteria. The model of using the E-Zine and email alerts to drive the portal and portlets respectively has resulted in growing bands of subscribers. Current data indicate that the project will break even at the end of the year 2004. Evidence of this, from the system logs, is now presented for the main portal, driven by the E-Zine, and the entertainment portlet, nightlive.

\begin{tabular}{|c|c|c|c|c|c|c|c|c|c|c|}
\hline \multicolumn{11}{|c|}{ Siınim.ily ly Voutlo } \\
\hline \multirow{2}{*}{ Pllnnth } & \multicolumn{4}{|c|}{ UDily'A*q } & \multicolumn{6}{|c|}{ Monthly I dtals } \\
\hline & I lit ₹ & I iles & Pהח 5 & Visits & stite 5 & kllytes & Visits & 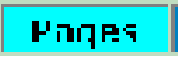 & I ilpe 5 & I lit 5 \\
\hline $6 \operatorname{sct} 2 \mathrm{U}+3$ & 4300 & $\therefore 1=0$ & $4=05$ & $51 \mathrm{~L}$ & $5:=1 c^{\prime}$ & 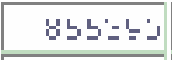 & $1=3 ゙-5$ & $=20300$ & יל4Lל & $1353 \mathrm{~L}$ \\
\hline '-三р 리: & $4 \triangleq U$ & $=-J^{\prime}$ & $4 \div 0=$ & 5,44 & $3+i<$ & U:U1_- & $1 \in J 41$ & $-4 / 2 \leq 44$ & ¿'́Utத & $1<i^{\prime \prime}=4$ \\
\hline "חרר? דו ה. & -74.7 & รศสT & רות & rin.r & $4 r \div$ & ורוז & וחר.". & r I I. & 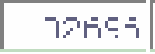 & 171.0 \\
\hline ברח: ال 1 | & דיה: & :5า.3 & $5 \div 67$ & $5.3 \%$ & |1F8. & 8PFF & If $5 \cap .3$ & 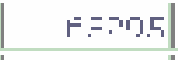 & |רוהדי| & $1=.3 \%$ \\
\hline 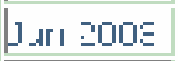 & 1375 & $-\because .55$ & IE75 & 531 & | $1 \varepsilon 0^{\circ}$ & $8073=1$ & $1 \bar{c}=25$ & $-1 \overline{-250}$ & $739 \equiv 3$ & $1 \cdot 62=2$ \\
\hline$p w=; 2[03$ & 4120 & 2279 & 4120 & +52 & $427 \div$ & $7735=2$ & 14720 & -27743 & 70675 & 127743 \\
\hline r 2008 & $57+4$ & E2?:- & $3^{i}<4$ & +25 & $4[35$ & 839555 & $1 \varepsilon 380$ & $-1 \varepsilon 321$ & נ51515 & $1123 \varepsilon 1$ \\
\hline pvler $20 J 3$ & 4594 & $19+5$ & 4592 & $35 \mathrm{C}$ & 4451 & $7=81[2$ & $1[361$ & $-42-44$ & $503 \mathrm{C} \div$ & $1-244$ \\
\hline$I \in O^{\prime} \mathrm{UJJ}^{\prime}$ & 4 4.ण & 19 Jب & $4 ! 01$ & 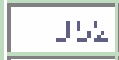 & 4101 & 2.1411 & $=$ JUU & $\because \angle L<B U$ & 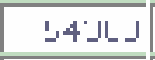 & 1 1ट4 - - \\
\hline Ian 깅: & : 14יוין & $1-1.1$ & |د & .41 & |יו:14: & . I:L. I & 14111 & إl & $4.1,1$ & ـا川 \\
\hline 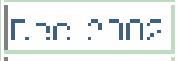 & $=5,11$ & | & $.3 .5: 1$ & $2.3 r$ & |.31:5 & & 7.7 & rr.sonil & 'RAF" & זיזדרו ו \\
\hline 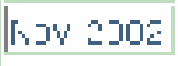 & 三790 & 1651 & ברחיכ & 257 & $3[0$ & $355 \Xi \mathrm{C} 1$ & 7730 & $-1 \equiv 798$ & .965. & 113053 \\
\hline Tnts & & & & & & ח & เรกศาร & I $\mathrm{Anz}$ Iก? & 7ศกวนศ & I \\
\hline
\end{tabular}

Figure 3 - Portal usage at the beginning of November 2003 
It is interesting to note that the number of visits is stabilising, although the number of page hits is decreasing as subscribers are more familiar with the layout of the site and do less random browsing. The EZine driven newsletter style of the main portal is essentially been seen as a B2B endeavour.

\begin{tabular}{|c|c|c|c|c|c|c|c|c|c|c|}
\hline \multicolumn{11}{|c|}{ Sidrrurliary toy Morilt } \\
\hline \multirow{2}{*}{ rlonth } & \multicolumn{4}{|c|}{ Inily A*ด } & \multicolumn{6}{|c|}{ Irlnnthly' Intals } \\
\hline & Hils & Filus & rayes & visils & Silts: & KBylus & |risils & 「dylos & Filus & Hils \\
\hline $0=1$ 200 & $|1750|$ & $130^{\top}$ & 1750 & $11 \cdot$ & דا & כ280 & $355:$ & $\Xi 518$ & $\mid c 533$ & $515: 3$ \\
\hline Ees 2003 & 2735 & 2275 & 2735 & 105 & 674 & 591515 & $3=67$ & $\varepsilon 2 J G G$ & $\operatorname{cEg7G}$ & $82[05$ \\
\hline 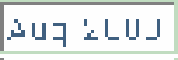 & 1304 & 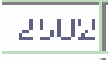 & 9114 & $\overline{\mathrm{UL}}$ & 31 & J'LL': J & 2144 & $=J=2 ! y$ & U⿻i口 & 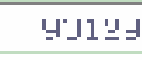 \\
\hline |ـ & $\tau$ & 1 & $T$ & $\perp$ & $\mathrm{IC}$ & ר: & 57 & 226 & 2 & ร25 \\
\hline נן & 1 & 0 & - & ] & $\overline{\mathbf{c}}$ & $1]$ & $\bar{c}$ & 21 & 6 & 21 \\
\hline rvla'v s'UU: & 1 & $\mathrm{u}$ & $=$ & 1 & 14 & $1 i$ & $1 \mathrm{LL}$ & $J^{\prime \prime}$ & 10 & 12 \\
\hline lotals & & & & & & 1/s1u:Jy & 뵈 $44^{\circ}$ & 2:10บ2'2 & IU64: & शรUu:2 \\
\hline
\end{tabular}

Figure 4 - The new Nightlive Portlet usage at the beginning of November 2003

In contrast to the main portal, the entertainment portlet, nightlive, is seen as a $\mathrm{B} 2 \mathrm{C}$ endeavour, and has found popularity since its launch in August 2003, with increased numbers of targeted visits and interactive features that appeal to its demographic (See Figures 3 and 4).

The action research approach has produced the following distinguishing design characteristics that have been adopted for the e-zine newsletter style portal and subsequent portlets. These have evolved through experience and appear to contributed to the success of the WBC. They would therefore be recommended for any similar project:

- All online activities are free to members with no subscription fees

- Income is generated through advertising with continuous dynamic banner advertising on all portal pages with linkages are only by paid banner advertisements. There is a high percentage $(50 \%)$ advertising mix in the HTML newsletter with not a single complaint after 14 months of weekly publications.

- The newsletter editorial content is targeted at the local community with non-mainstream opinion pieces provided by a mixture of professional and amateur journalists

- Traffic driven by permission-based HTML emails ie the delivery is pro-active not reactive and independent of other paid media support. Most new subscribers come from word of mouth recommendations together with the use of occasional competitions to attract volunteered email addresses of new subscribers.

- There would be no chatroom or open for a with all online dialogue moderated so that participants are unable to conduct 1:1 (face to face) discussions with unidentified persons

- No external links to Search Engines, as this leaks traffic off site,

- Online services not to duplicate or compete with established players eg Yellow Page directories

- The specific portlets are demographically positioned by interest in this case local sport and youth entertainment.

The following section discusses both the sustainability of this project and the potential for new projects using this basic model in different settings. 


\section{Current Developments and Flow on Cases}

\subsection{Developments of the initial case}

In 2004 the initial regional WBC has continued to thrive. With a high volume of traffic ensuring continued paid advertising the project has stabilised as a viable business enterprise. It has however not been static. The small management group has continued to review and revise the general approach leading to some specific new functionality within the consistent philosophy of the newsletter style portal.

The first major change was a basic one to replace the specific domain name 'Wollongong OnLine' with a generic one 'Your Online Community' so that 'www.wollongongonline.com' has become 'www.wollongong.youronlinecommunity.com.au'. This sets a platform for the establishment of new WBC projects in different regions, one of which has already been launched as will be described below. It is interesting that the Australian government is also considering the significant of domain names to reinforce local identity in its One City One Site (OCOS) project (OCOS 2004).

As shown in Figure 5 there is currently a new look Wollongong Online portal with the new design a response to feedback from users. A new feature 'Your Smart Pages' has been added to provide a suite of tools and new services that are for payment and not free to general subscribers. These include a facility for users to design their own website, place classified advertisements and place entries into the community calendar. There is still not chat or general discussions forum, as in the original approach but community involvement and feedback has increased with a visible influence on the site.

The business management regularly gave thought to the prospect of extending their sphere of operations into new markets. One such venture into suburban areas of a major city was seriously considered for some time and in 2004 is being implemented as described below. The prospect of moving into smaller country towns was not given immediately consideration due to the difficulties envisaged with viability in a smaller market while the product was still being developed with associated costs. However it was not discounted entirely and an attempt by another small business to set up an online community in a nearby small town is also described below. The comparison between the issues involved is then made in the following discussion.

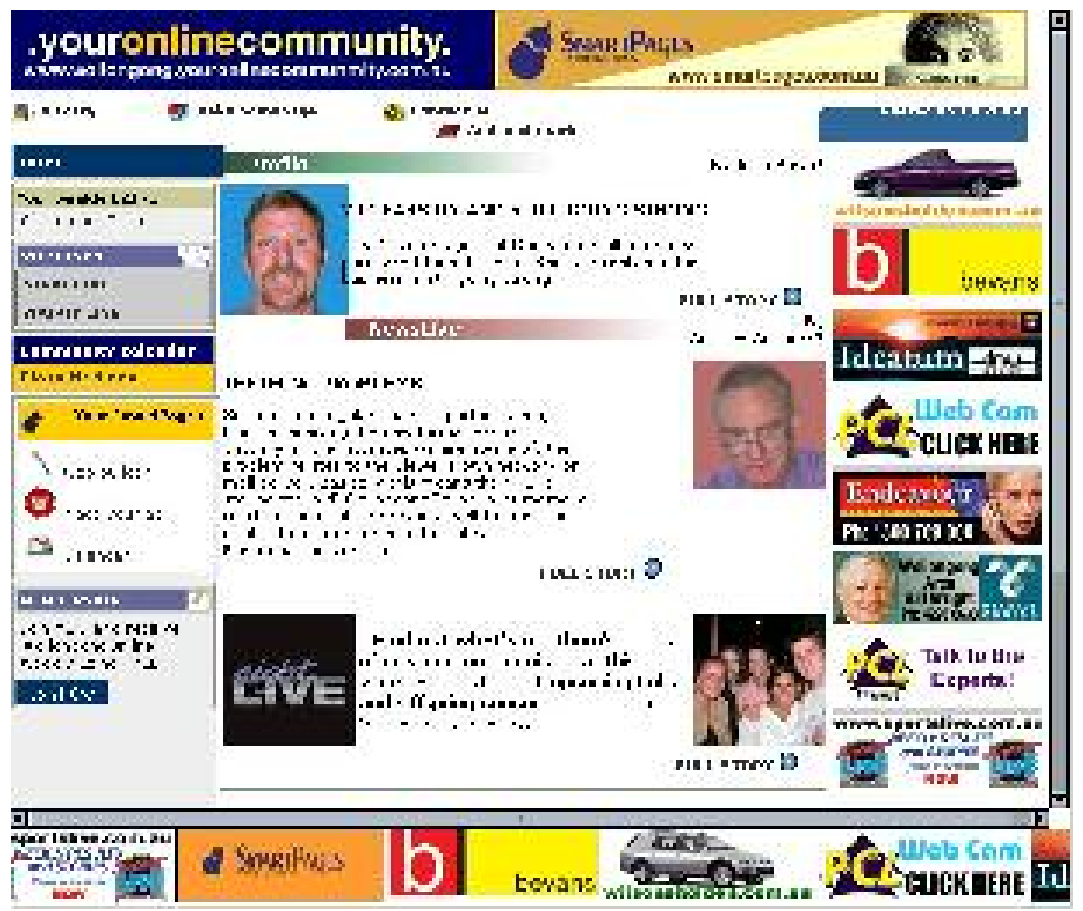

Figure 5 The new look Wollongong Online portal 


\subsection{Issues of scaling up}

Late in 2003 the decision was made to change the initial site designation from the location specific 'Wollongongonline' to the generic 'YourOnlineCommunity'. This opened the way to expand the business into other markets and a decision was made to investigate the prospects of creating a community in Greater Sydney. The municipality of Parramatta an area of suburbia in the Western part of Sydney see URL: www.parramatta.youronlinecommunity.com.au was chosen as the optimal area to attempt to expand the business model. This new WBC was potentially a much larger, but less well-defined, market roughly $50 \%$ larger by number but with a different demographic and a different concept of local community. As citizens of Sydney, a very cosmopolitan city on the world stage, subscribers would probably be more sophisticated with a broader range of interests and connections perhaps requiring a corresponding more up-market look and feel. Identifying the actual geographical area to target was a challenge. Consideration was given to using a footprint based on support for a local football team in the national competition or the distribution area of the local weekly paper.

The new project utilised the tested 'WollongongOnline' model of the newsletter style e-zine with the Nightlive and Sportslive portlets. A locally based publisher/investor from the Parramatta area became involved and a great deal of meetings, market evaluations and garnishing of support ensued. The project went live in May 2004, as shown in Figure 6, and uptake is being monitored. Preliminary evidence is showing that traffic to the site already nearly equals the Wollongong site's in its first 2 months of operation.

Interestingly the SportsLive portlet which now emphasises reporting and photos as opposed to being results driven is exceeding its counterpart results ie traffic to the shared portlet has over doubled. NightLive does not appear to be experiencing the same level of popularity as of July 2004.

The long-term prognosis for the project appears greatly improved since it recently attracted the attention of top management of some large Sydney-based media companies. These are big players in the print business stuck in the traditional newspaper 'legacy based' paradigm or the Minimal Disruption Model (Jones M 2001) described in his doctoral thesis. The 'your online community' project has aroused their curiosity and they are anxious to learn from it so that preliminary investigations of an alliance are under consideration.
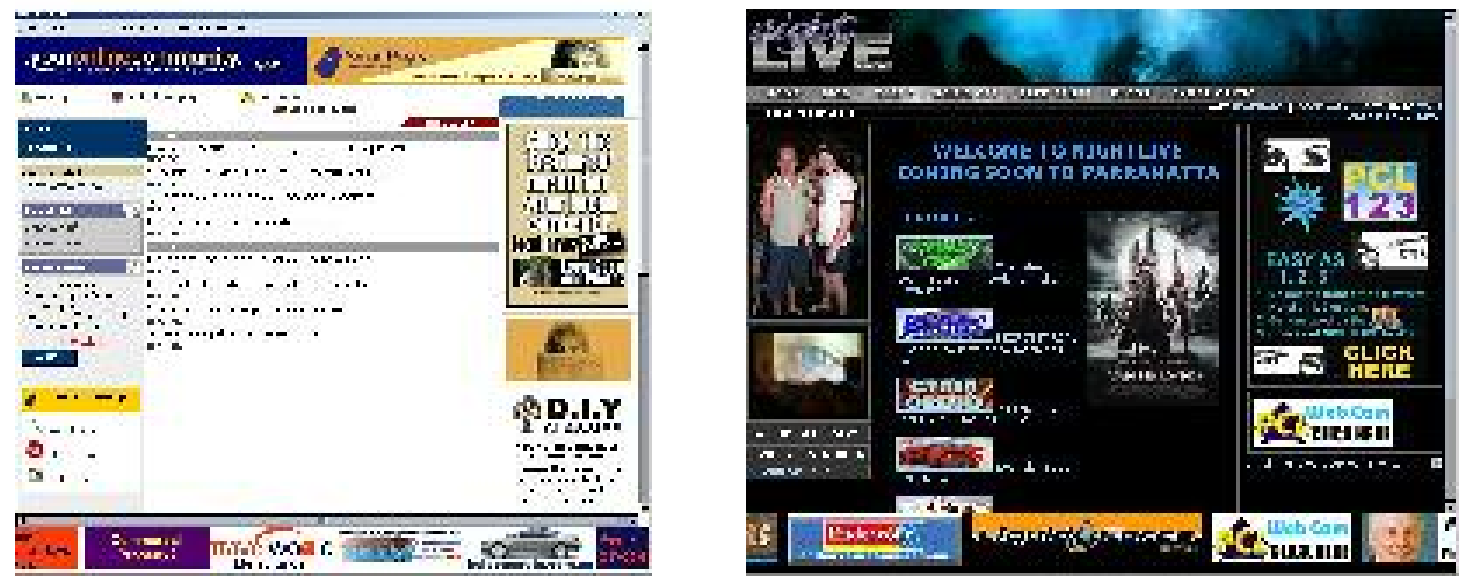

Figure 6 The Newslive and Nightlive Screens from the Parramatta site.

\subsection{Issues of downsizing}

To provide a balance to the research a case is now described of a project to create a commercially viable WBC in much smaller market in a small coastal town of Ulladulla. There are at most 10,000 potential subscribers in the town and nearby countryside. There has always been a strong sense of local identity in this region, which has traditionally been centred around a fishing village. There is no large business in the area which is dominated by small businesses in fishing, tourism and hospitality as well as businesses that provide gods and services for the local population. There is a local high school, hospital, radio and weekly newspaper. Notably the population includes a major influx of tourists over the summer and increasing 
Connery A. and Hasan H. (2005) Social and Commercial Sustainability of Regional Web-based Communities, Journal of Web-Based Communities 1/3 246-261.

numbers of retirees and 'seachange' families are now moving into the area. There are many local issues of common interest including the environment, the drift of youth to the cities, and the effect on business of the limited tourist season so it is likely that in this area the e-zine would be of interest as would Sportlive but not Nightlive. A significant demographic in the area involves the retiree and other seniors who are growing in their use of the Internet and have the time in retirement to engage in pursuits such as genealogy, writing, painting, photography and so on. The challenges here would be to evolve the WBC model so include such other portals and to test if the market sufficient to make a WBC commercially viable where limited numbers of local advertisers now have radio and a newspaper.
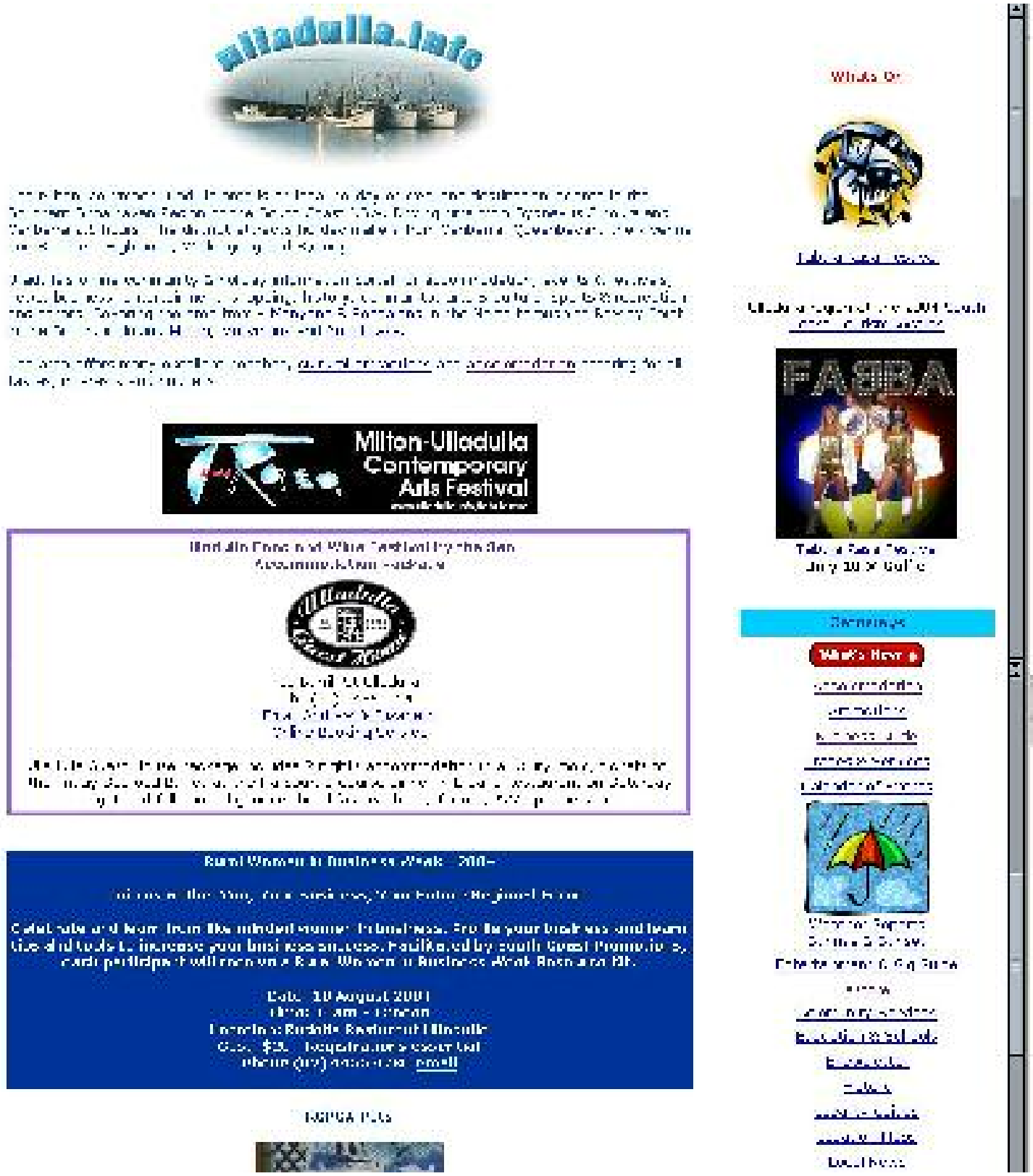

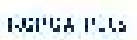

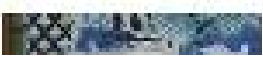

Figure 7 Ulladulla.info 
There have already been a number of attempts to set up a local website to act as a WBC which have not been sustainable. There is a new one that has recently been developed as 'www.Ulladulla.info', shown in Figure 7 that has some similarity with the model of wollongongonline with local advertising and news. A regular newsletter is produced and sent out by email but it is not an e-zine in the sense that it links back to the portal. There is however more opportunity for interaction as a community forum is provided. This was originally open to all and unmoderated, which attracted some undesirable content. There is now a subscriber only, moderated forum facility that is gaining in popularity.

\section{Discussion}

The initial project at Wollongong has clearly demonstrated both its social and commercial value, the latter being reflected in its increasing viability. It is interesting to note that while the social value was readily acknowledged by the community, there was always scepticism from local businesses regarding its moneymaking potential. This is revealing from a business perspective but also from the research perspective where we are now able to develop a useful model of this type of WBC and confirm the main issues that should be considered. While many web based communities are set up by enthusiastic amateurs, with some private support or with sponsorship of government or research funding this project was established from the outset as a business venture. A business needs to identify markets, produce an income stream, build up a customer base and develop and continue to improve its product offerings. It was fortuitous that in-depth marketing/publishing expertise was available to the project but also that there was also a strong awareness of the needs and character of the local community. WollongongOnline deliberately aimed to serve the day-today information needs of the local community without competing with other existing traditional media such as the local paper, radio, TV or community noticeboards. This is an extension of areas in which many traditional broadcast media have been to some extent interactive, such as letters to the editors and talkback radio. There is a current trend towards a coming together of TV and the Internet with many stations having interactive facilities on their website. There will no doubt be more exploration of other schemes, which can take advantage of Internet technology to provide an exciting cost effective service that can engage with the community and meet a need.

The business model is predicated on producing an income stream from local advertising based on the level of activity, which it is therefore necessary to monitor. It is a subscriber based service with quality locally generated content and facility for reader comment and feedback but not open discussion. Subscribers receive the weekly e-zine in their email to entice their patronage of new content. They are encouraged to recruit new subscribers with competitions and flyers are circulated at sports functions and nightspots but no (mass) advertising is used. Other portlets, such as sport and youth entertainment, need to be created to engage clearly identified demographics in the community. At the same time there is a sense of awareness of community values and the due application of the basic characteristics of communities which operate online: common interest, social capital and economic value.

While this approach is currently successful in the Wollongong case, time will tell whether it is sustainable and transferable. For the former issue, continued feedback from the community is allowing it to evolve as both the technology and the community changes. For the latter, the two secondary cases presented here will help to determine how the model can adapt to different communities. Costs to produce a second site will always be much less than the first where the upfront design and development are sunk costs. Fixed and variable costs do not increase proportionately with size but the potential for income does. A major area of interest is to understand how size of community influences viability with the need to balance the need for income with the need for a coherent social identity.

The other major driver of a WBC is the enthusiasm for the project that is evident in the development phase. Is this essential and if so what will happen once this style of WBC goes beyond the early adopter stage. Will there be people who are community socially minded, have business knowledge plus the foresight of what the new technologies can offer and the ability to manage the technology/business/community mix? The rewards for this project are certainly not primarily financial but rather the satisfaction of being a leader in new and exciting endeavour creating something worthwhile for the community. It may even be that this work can drive social change in renewing a sense of community meeting needs in the city, town and country. 
Connery A. and Hasan H. (2005) Social and Commercial Sustainability of Regional Web-based Communities, Journal of Web-Based Communities 1/3 246-261.

\section{References}

Arthur Anderson (1999) On-Line Communities in Business, Report from the On-Line Communities Research Study, Connery A, Hasan H (2004) Sustaining a Locally-based Virtual Community, Proceeding of IADIS04, Lisbon.

Cothrel Joseph and Williams Ruth (1999) Next Generation Research Group Arthur Andersen On-Line Communities in Business

Dennis, A. R. and Kinney, S. T. (1998). Testing media richness theory in the new media: The effects of cues, feedback and task equivocality. Information Systems Research, 9(3), 256-274.

Hasan H. and Crawford K. (2003a) A multifaceted approach to distributed communities of learning and practice. Proceeding of the IS Perspectives and Challenges in the Context of Globalization Conference, Athens, June 2003 for IFIP WG 8.2 and WG 9.4

Hasan H. and Crawford K. (2003b) Socio-Technical Systems for Knowledge Mobilisation in Communities, Proceeding of ACIS2003, Perth.

Jones K. M. (2001) The Application of the Internet as a Delivery System for News and Journalism. PhD Thesis, University of Wollongong.

Koh Joon and Kim Young-Gul (2001) Sense of Virtual Community: Determinants and the Moderating Role of the Virtual Community Origin, $22^{\text {nd }}$ International Conference on Information Systems, 407-409.

Millen David R \& Patterson John F (2002) Stimulating Social Engagement in a Community Network, Proceedings of CSCW02, November New Orleans, 306-313.

Novak David (2003) The Evolution of Internet Research, Online , 27/1 , 18-22.

O’Donnell D., Porter G., McGuire D., Garavan T., Hefferman M. and Cleary P. (2003) Creating Intellectual Capital: a Habermasian Community of Practice Introduction, Journal of European Industrial Training, 27/2 80-87.

OCOS (2004) Discussion Paper available at http://www.auda.org.au/pdf/sub-ocos.pdf (Accessed July 2004)

Preece Jenny (2000) Online Communities Designing Usability, Supporting Sociability John Wiley \& Sons Ltd Chichester, UK

Raeside R., Walker J. (2001) Knowledge: The Key to Organisational Survival, Measuring Business Excellence, 5/3 5559.

Rheingold Howard (2002) Smart Mobs: The Next Social Revolution, Perseus Publishing.

Skogseid Ingerd and Jansen Arild (2001) Booktowns on the Internet: Rural Enterprises enter the Network Society, $22^{\text {nd }}$ International Conference on Information Systems, Brisbane, 385-393.

Stoel L (2002) Retail cooperatives: group size, group identification, communication frequency and relationship effectiveness, Int Journal of Retail \& Distribution Management 30/1 51-60.

Suh, K., Hasan, H., Couchman, P. K., and Lee, D. (2003). Exploring social interaction in Web-mediated communication. In H. Hasan, Gould, E., and Verenikina, I. (Eds.), Information systems \& activity theory volume3: Expanding the horizon. (pp. 141-155). Wollongong, Australia: University of Wollongong Press.

Vrazalic L. Hyland P. MacGregor R. and Connery A.(2003) Regional Community Portals: Analysing the current state of play using the $\mathrm{S}_{3}$ model, Proceedings of the $5^{\text {th }}$ International IT in Regional Areas Conference, December, Perth.

Walsham, G. (1995) Interpretive case studies in IS research: Nature and method, European Journal of Information Systems, 4/2, 74-81.

Wenger E. McDermott R. Snyder W. (2002) Cultivating Communities of Practice, Harvard Business School Press, Boston. 